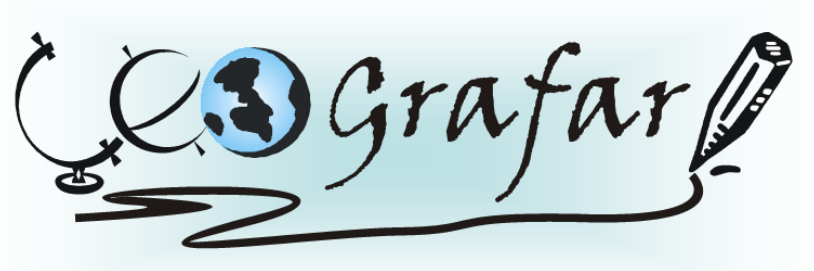

Revista Eletrônica do Programa de Pós-Graduação em Geografia - UFPR

\title{
ANÁLISE DA DISTRIBUIÇÃO PLUVIOMÉTRICA NA CIDADE DE SALVADOR E SEUS IMPACTOS AMBIENTAIS: O CASO DOS DESLIZAMENTOS EM SÃO CAETANO NO PERÍODO DE 2007 A 2012
}

\section{ANALYSIS OF THE RAINFALL DISTRIBUTION IN THE CITY OF SALVADOR AND ITS ENVIRONMENTAL IMPACTS: THE CASE OF LANDSLIDES IN SÃO CAETANO IN THE PERIOD FROM 2007 TO 2012}

Rejane Bao Geógrafa

Universidade Católica do Salvador

Salvador, BA, Brasil e-mail:rejabao@hotmail.com

Dante Severo Giudice

Prof. Dr. do curso de Geografia da Universidade Católica do Salvador

Geólogo da CBPM

Salvador, BA, Brasil e-mail: dasegu@gmail.com

\begin{abstract}
RESUMO
Salvador, assim como várias cidades brasileiras, sofrem com a ocupação desordenada em áreas de relevo acidentado, trazendo inúmeros problemas para a população como os deslizamentos, principalmente no período de maior pluviosidade. Os problemas ambientais atingem todos os níveis da população, mas os impactos de maior gravidade estão registrados na população de classe menos favorecida que sofre com a falta de infraestrutura e a falta de acesso a locais apropriados para moradia. É importante analisar os índices pluviométricos de uma cidade para compreender o comportamento dos deslizamentos. O presente estudo traz uma análise dos deslizamentos ocorridos na região administrativa de São Caetano com índices pluviométricos registrados na cidade de Salvador no período de 2007 a 2012. Para a realização dessa pesquisa foram utilizados dados de chuva das nove estações pluviométricas de Salvador, disponibilizados pelo Instituto de Meio Ambiente e Recursos Hídricos, como também, informações de ocorrências de
\end{abstract}


deslizamentos da região administrativa de São Caetano, cedidos pela Defesa Civil de Salvador (CODESAL). Os resultados obtidos através dessa pesquisa mostraram uma correlação entre os deslizamentos e a pluviosidade, pois a maior parte dos deslizamentos ocorreu em período de maior pluviosidade. Com isso percebe-se que é fundamental conhecer as causas dos deslizamentos para tomar medidas que possam prevenir ou amenizar os danos causados a população.

Palavras-chave: Deslizamentos, Pluviosidade, Impactos Ambientais.

\begin{abstract}
The city of Salvador, as well as many others Brazilian cities, suffers with the uncontrolled urban occupation of steep terrains. That results in many problems to the local population like landslides, mainly during the rainfall season. The environmental impacts of these landslides harm the city in a whole but the poor local inhabitants are the major victims of that, suffering with the losses of their houses and the dismantling of the already poor infrastructure. It's important to study the rainfall patterns of a city to understand the landslides behavior. This paper presents the analyses of the landslides that occurred in the São Caetano neighborhood, together with the pluviometrical indexes recorded in the city of Salvador from 2007 to 2012. For that were used the data of the nine rain gauges of the city and the record of the occurrences of landslides of the area in the period. The analyses of all these data show a correlation of the landslides with high indexes of pluviosity. That shows that is important to understand perfectly the causes of the landslides in order to prevent or at least diminish the harms to the local population.
\end{abstract}

Keywords: Landslides, Pluviosity, Environmental Impacts.

\title{
INTRODUÇÃO
}

O processo de urbanização no Brasil ocorreu de forma intensa e desigual. A oportunidade de viver bem nas grandes cidades, não é igual para todos, pois grande parte da população menos favorecida, é obrigada a ocupar áreas impróprias para moradias. Devido à falta de planejamento e de organização na ocupação urbana, a população é exposta a ocorrências de acidentes como os de deslizamentos.

A cidade de Salvador, hoje a terceira maior capital do Brasil, com aproximadamente três milhões de pessoas, assim como em outras capitais brasileiras, teve um dinâmico processo de urbanização nos últimos anos. Juntamente com o crescimento da população, aumentou a falta de recursos, carência de infraestrutura, falta de políticas habitacionais que levou a população a 
ocupar áreas desfavoráveis, aumentando cada vez mais o risco de deslizamentos, principalmente nas áreas habitadas pela população pobre.

Os deslizamentos em áreas urbanas são resultados da degradação ambiental que é potencializada pela ação humana. As consequências mais notáveis e marcantes dos deslizamentos em áreas ocupadas são as perdas de vidas humanas e ferimentos de pessoas presentes nas áreas de ocorrências, mas eles também causam perdas sociais e econômicas.

Para estudarmos o processo e as ocorrências de deslizamentos é necessário identificar e analisar a distribuição pluviométrica no decorrer do tempo em uma cidade. A análise da pluviosidade é essencial para explicar os acontecimentos de deslizamentos servindo para o planejamento urbano, amenizando os danos causados à sociedade.

O objetivo desse trabalho é analisar, temporal e espacial, o comportamento das precipitações relacionando-o com as ocorrências de deslizamentos na área urbana de Salvador, com foco na região administrativa de São Caetano, no período de 2007 a 2012.

O presente trabalho pretende contribuir para a sociedade, pois com o estudo da distribuição das precipitações teremos condições de melhorar o planejamento urbano identificando os locais mais críticos do bairro em análise e os meses com maiores ocorrências pluviométricas para a prevenção de problemas gerados pelos deslizamentos. Em termos acadêmicos, em função da ampliação dos conhecimentos sobre a distribuição espaço-temporal das chuvas de Salvador e das ocorrências de deslizamentos no bairro São Caetano, a presente investigação servirá de embasamento teórico para o desenvolvimento de futuros trabalhos.

\section{MATERIAIS E MÉTODOS}

Os deslizamentos de encostas têm aumentado muito, principalmente nos centros urbanos dos países emergentes, onde os movimentos de massa são agravados em decorrência da intensa urbanização e construções acentuadas em encostas (ROSA FILHO, 2008).

Os procedimentos metodológicos adotados no desenvolvimento desse trabalho são o estatístico, o comparativo e o histórico onde serão utilizados dados totais mensais e anuais da precipitação pluviométrica de nove estações, fornecidos 
pelo Instituto de Meio Ambiente e Recursos Hídricos (INEMA) no período de 2007 a 2012. Serão usados também dados dos eventos de deslizamentos ocorridos na região administrativa de São Caetano, disponibilizados pela Defesa Civil de Salvador (CODESAL).

Através do método estatístico serão elaborados gráficos que possibilitarão uma maior visibilidade nas ocorrências de pluviosidades e de deslizamentos na região administrativa de São Caetano, assim como, localizar os bairros que obtiveram maiores problemas de deslizamentos durante o período analisado.

O método comparativo servirá para avaliar os dados entendendo 0 comportamento dos eventos de pluviosidade e dos deslizamentos ocorridos no período analisado para que possamos verificar se as ocorrências de deslizamentos estão situadas sempre nos mesmos locais, e se a relação pluviosidade $x$ deslizamentos estão correlacionados.

Com o presente trabalho serão investigados os acontecimentos de deslizamentos e pluviosidade ocorridos no período analisado assim como os problemas causados a população decorrente dos mesmos.

\section{GESTÃO DE RISCO DE DESLIZAMENTOS NO BRASIL}

No Brasil já foram registradas milhares de ocorrências de deslizamentos em várias cidades, com muitas mortes, pessoas desabrigadas e muitos prejuízos oriundos dos deslizamentos. Segundo o Guia de prevenção das cidades são os deslizamentos que geram o maior número de vítimas fatais nas cidades.

As perdas em decorrência aos deslizamentos ocorre predominantemente em áreas urbanas tendo um aumento considerável a partir da década de 80 . Fato ocorrido devido à ocupação acelerada e na maioria das vezes sem planejamento de áreas expostas a deslizamentos, isso nas grandes cidades e nas regiões metropolitanas (SANTOS 2007). Dados do Instituto de Pesquisas Tecnológicas de São Paulo (IPT) contabilizou no ano de 1988, 277 vítimas fatais de deslizamentos no Brasil.

Segundo Santos, citado por Almeida e Pascoalino (2009), o Brasil é afetado por desastres naturais, mas não por desastres de origem tectônica, como os terremotos, os tsunamis ou derrames vulcânicos; nosso país é atingido por 
desastres que estão relacionados a fenômenos climáticos que são potencializados pela ação do homem com destaque as enchentes e os deslizamentos.

O Brasil é um dos países mais atingidos por fenômenos naturais perigosos. Em 2008, o país ocupava o 13a lugar entre os países mais afetados, tendo pelo menos dois milhões de pessoas atingidas por desastres naturais que estão atrelados a processos atmosféricos, como as precipitações pluviométricas. (ALMEIDA; PASCOALINO 2009)

No Brasil tem crescido as preocupações com a gestão de risco, no âmbito de proteção, previsão e prevenção de ocorrências. Mas além das iniciativas pontuais, pouco se tem feito para criar uma cultura de risco pautada no conhecimento, na consciência e na memória de risco (ALMEIDA; PASCOLINO 2009).

A organização da defesa civil no Brasil existe desde 1988, quando foi criado o Sistema Nacional de Defesa Civil (SINDEC), que foi reorganizado em 1993 e atualizado somente em 2005 atribuindo aos órgãos e entidade da administração federal, dos Estados, do Distrito Federal e dos Municípios; às entidades privadas e a comunidade; responsabilidades pelas ações de defesa civil em todo estado nacional.

Algumas ocorrências de deslizamentos no Brasil chamam atenção devido ao alto grau de impactos causados as cidades atingidas. No estado de Santa Catarina, em Novembro de 2008, as fortes chuvas resultaram em mais de 80 mil pessoas desabrigadas ou desalojadas, atingindo 63 munícipios em situação de emergência, 14 em estado de calamidade pública e 135 mortes (CAROLINE; MARGARIDA 2009). Esse episódio bloqueou quase todas as estradas das regiões afetadas, causando impactos ambientais, econômicos e sociais nas cidades atingidas.

Os eventos ocorridos no estado do Rio de Janeiro em janeiro de 2011 esteve entre os principais noticiários do mundo em decorrência dos eventos ocorridos. Foram registrados diversos deslizamentos e alagamentos em sete municípios da região Serrana, deixando mais de 900 pessoas mortas e milhares de pessoas desabrigadas. De acordo com Busch e Amorim (2011), esse desastre natural foi considerado a maior catástrofe climática e geotécnica do país. Classificado pela ONU como o $8^{\circ}$ maior deslizamento ocorrido no mundo nos últimos 100 anos, sendo comparado com o desastre de Santa Catarina e pelo furacão Katrina em New Orleans nos Estados Unidos em 2005. 
Em síntese, são diversas as ocorrências de deslizamentos no Brasil resultando muitos prejuízos. Diante disso, a gestão de risco no Brasil tenta promover a participação local na questão dos desastres naturais, mas existem muitas fragilidades na implementação das políticas públicas, revelando que os municípios não possuem estruturas e condições mínimas para a aplicação da gestão de risco (ALMEIDA; PASCOLINO 2009).

\section{GESTÃO DE RISCO DE DESLIZAMENTOS NA CIDADE DE SALVADOR}

Segundo Gonçalves citado por Bitar (1995) e Giudice (2011), os problemas oriundos aos deslizamentos em decorrência a influência antrópica, ocorre em Salvador desde 1671, como podemos verificar no ofício lançado na Câmera de Vereadores da Comarca da Bahia que atribuía às ocorrências dos deslizamentos ocorridos na época, ao homem. E conforme citado, os acontecimentos de deslizamentos nas ladeiras da Conceição e Misericórdia (Cidade Baixa) ocorria devido às imundices lançadas nas ladeiras. Com isso, podemos perceber que o homem vem modificando o ambiente em que vive, tornando-o assim mais propício a riscos de deslizamentos.

Santos (2010) relata que a ocupação de Salvador iniciou ao longo das vias e pontos mais elevados dos terrenos, de forma menos agressiva onde as casas tinham quintais nos fundos e eram organizadas de forma harmoniosa. Com o crescimento da população e a necessidade de terras e locais para morar, foram se perdendo os quintais dando lugar as casas. As inclinações acentuadas dos terrenos, ao redor de $23,2^{\circ}$, passaram a ser a única opção de moradia, e de forma precária foram sendo construídos casebres de madeira que consequentemente favoreceu o crescimento do volume de lixo acumulado nas encostas, fatos que levaram aos deslizamentos e milhares de pessoas desabrigadas e mortas ao longo dos anos.

Segundo Santos apud Oliveira (2006), os problemas de deslizamentos iniciaram na região da falha geológica de Salvador, falha que separa a cidade alta da cidade baixa, e com o decorrer do tempo espalhou-se por toda cidade, principalmente na periferia. A cidade apresenta pouca oferta de terrenos adequados para a construção, livres de preservações, desapropriações e que possuam documentação legal de construção, infraestrutura urbana básica e topografia 
apropriada. Essas áreas são raras em Salvador e aquelas que ainda restam, possuem o preço elevado, tornando-se inacessível a população de baixa renda.

De acordo com Peixoto apud Costa (2012) e Giudice $(2011$; 2012) as encostas da cidade de Salvador apresentam inclinações entre $14^{\circ}$ e $27^{\circ}$, com média em torno de $23,2^{\circ}$. Constituem em diferentes tipos de formas de terreno, originados pela ação de forças externas e internas, através de agentes geológicos, climáticos, biológicos e humanos que vem modificando a superfície da terra.

Para Girão et al (2007), é importante identificar os locais e os processos que ocorrem instabilidades em ambientes com declividade em áreas urbanizadas, principalmente nos bairros periféricos da cidade, para que ocorra planejamento ambiental, levando em consideração não só diretrizes voltadas ao meio físico, mas também o meio social que haja interação entre o meio-ambiente-urbano.

Visualizando a cidade do Salvador, observa-se a quantidade de ocupação nas encostas e a aglomeração de casas nas mesmas. Tais fatos nos levam a perceber que ao longo dos anos, os planos e programas implantados para solucionar esses problemas não foram suficientes e o número de áreas de risco cresceu, assim como os acidentes decorrentes de deslizamentos.

\section{DESLIZAMENTOS NA REGIÃO ADMINISTRATIVA DE SÃO CAETANO}

Segundo o PDDU - Plano Diretor de Desenvolvimento Urbano, a cidade do Salvador é dividida em 18 regiões administrativas - RA (figura 1), as quais são RA I Centro, RA II - Itapagipe, RA III - São Caetano; RA IV - Liberdade; RA V - Brotas; RA VI - Barra; RA VII - Rio Vermelho; RA VIII - Pituba/Costa Azul; RA IX - Boca do Rio/Patamares; RA X - Itapuã; RA XI - Cabula; RA XII - Tancredo Neves; RA XIII Pau da Lima; RA XIV - Cajazeiras; RA XV - Ipitanga; RA XVI - Valéria; RA XVII Subúrbios Ferroviários e a RA XVIII - Ilhas de Maré e dos Frades (Figura 1).

A Defesa Civil de Salvador - CODESAL, utiliza como sistema de distribuição espacial dos deslizamentos na cidade, a divisão do município em 18 regiões Administrativas, que é chamada de SIGA (Serviço Integrado de Atendimento Regional). A região trabalhada é a RA III ou SIGA III - São Caetano, que é justamente uma das regiões que possui a maior quantidade de ocorrências de deslizamentos do município nos últimos anos. 


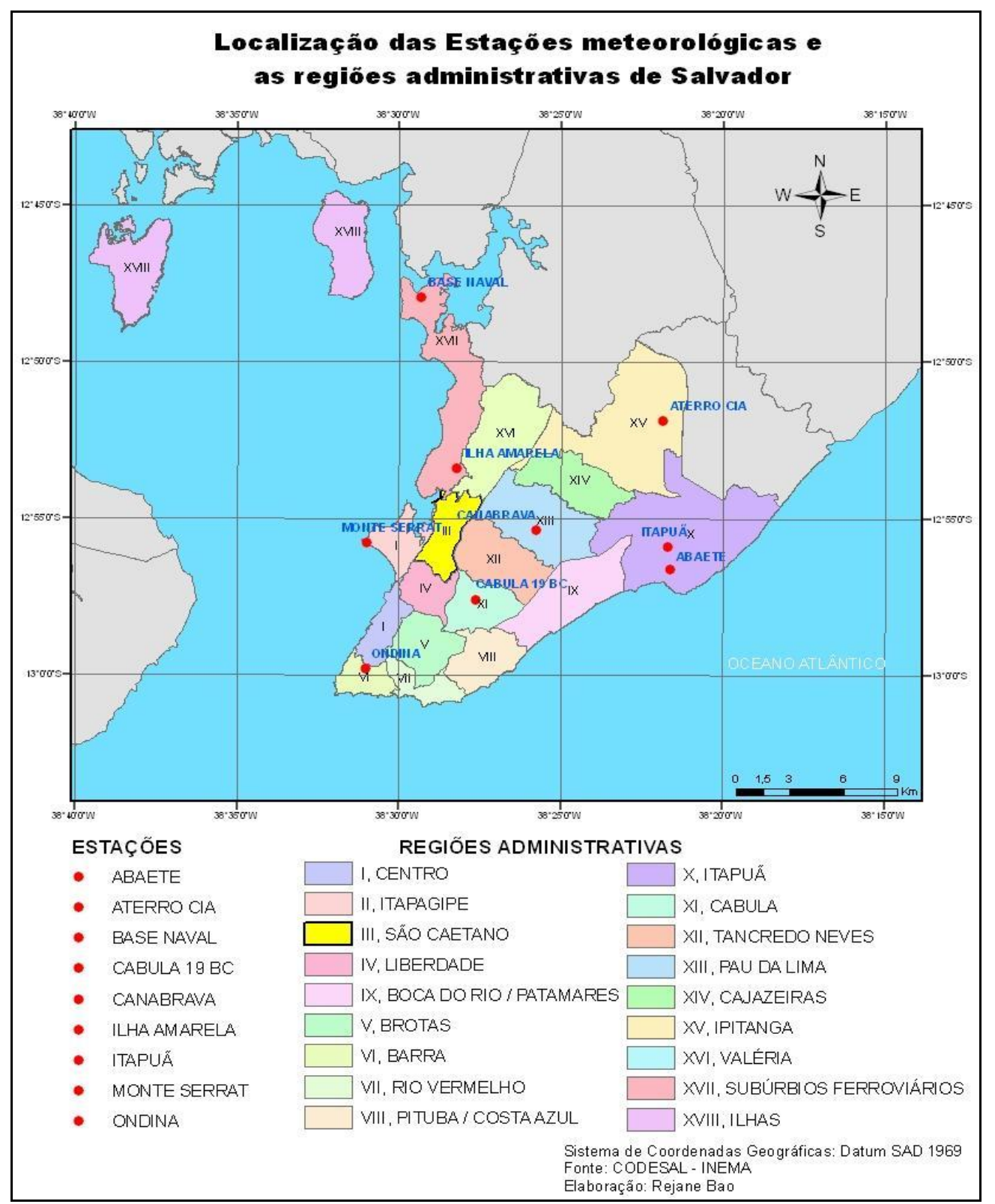

Figura 1: Localização das estações meteorológicas $e$ as regiões administrativas de Salvador. Fonte: CODESAL - Defesa Civil

O SIGA III abrange os bairros de Alto do Cabrito, Alto do Peru, Bela Vista do Lobato, Boa Vista de São Caetano, Boa Vista do Lobato, Bom Juá, Campinas de Pirajá, Capelinha de São Caetano, Fazenda Grande do Retiro, Jaqueira do Carneiro, Jardim Lobato, Lobato, Marechal Rondon, Plataforma, São Caetano. A área administrativa de São Caetano - RA III, é a região com maior população de Salvador.

A região trabalhada está implantada em dois platôs a meia encosta, paralelos às curvas de níveis do terreno, área inserida em trecho da falha geológica de 
Salvador, com predomínio de rochas do embasamento cristalino, possuindo pedreiras desativadas. Apresenta solos areno-argilosos, com características a instabilidade estrutural, o que contribui, devido a ocupação indiscriminada, nos períodos de maiores índices pluviométricos, para a instabilidade das encostas.

Os deslizamentos na RA de São Caetano apresentam perigo as moradias da região, assim como, a população que circula e reside no local. As ruas da região são prejudicadas em decorrências aos deslizamentos (Figura 2). No final de linha do bairro São Caetano (Figura 03) observa-se moradias irregulares com deslizamentos atingindo as mesmas.

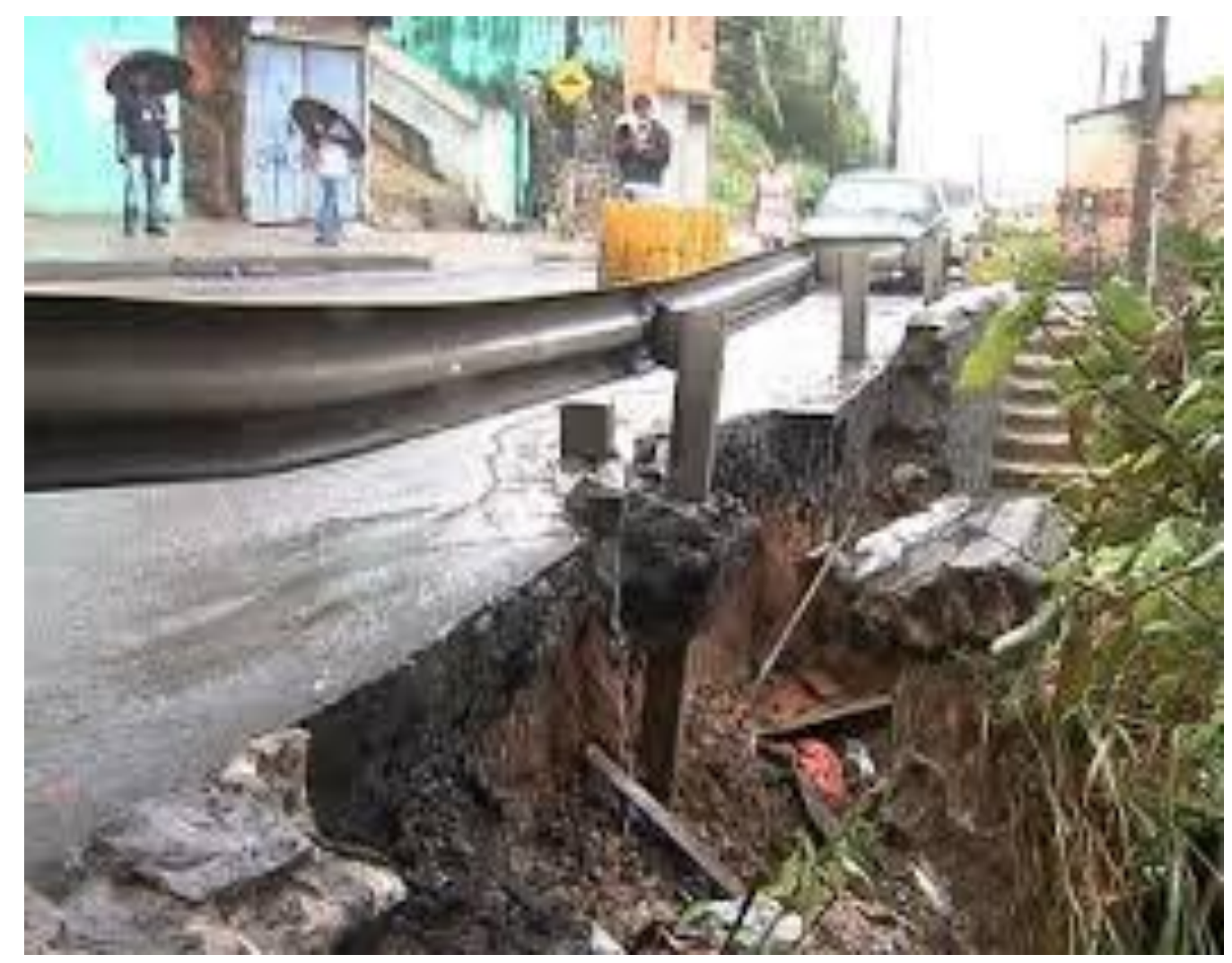

Figura 02: Deslizamento na Rua General Siciliano, Ladeira do Cacau na RA de São Caetano. Fonte: Página do g1.globo.com/bahia. 


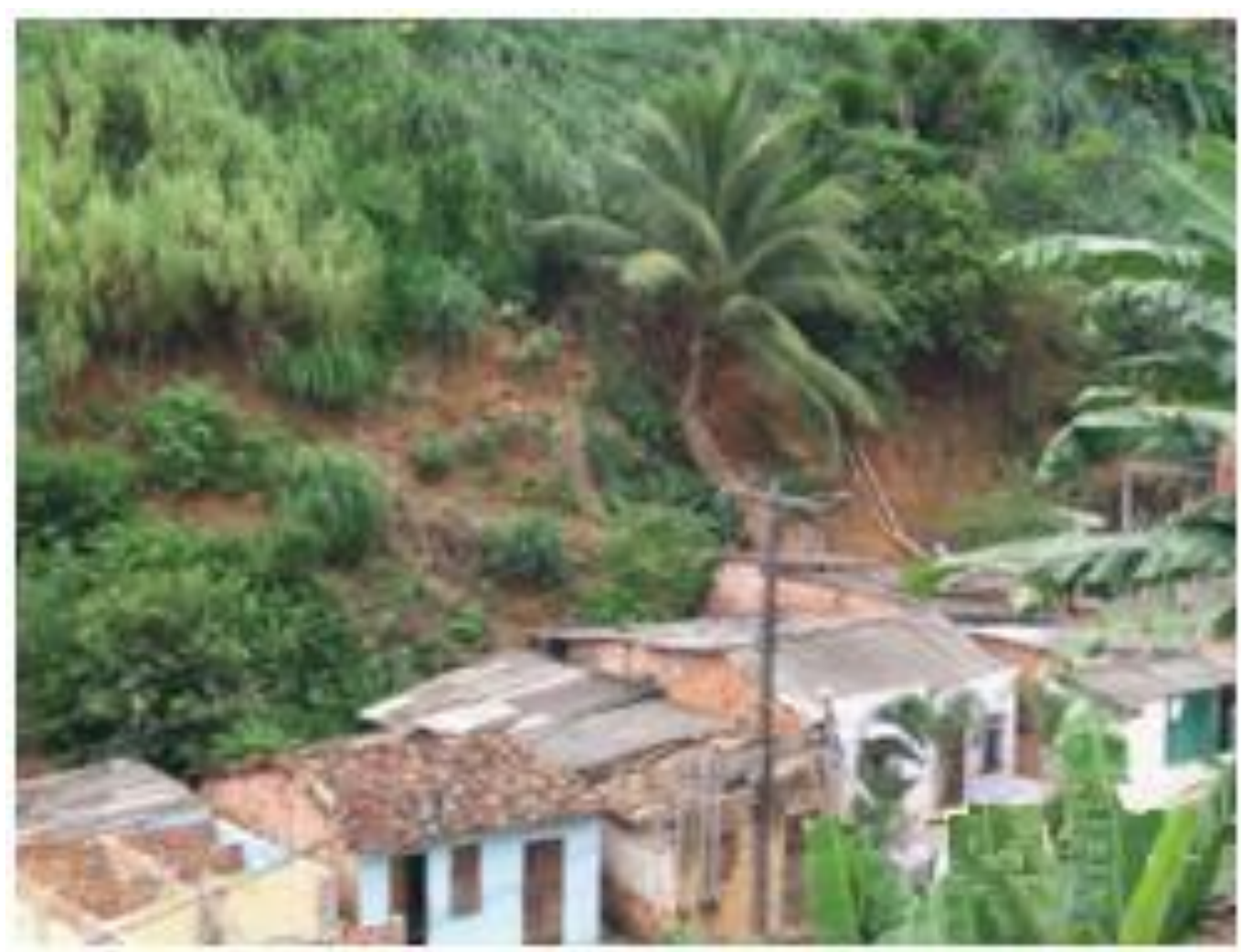

Figura 03: Deslizamentos no final de linha do bairro de São Caetano - RA São Caetano. Fonte: SOUZA, Adelaide Cerqueira.

Constitui-se na região com maior densidade territorial no Município, onde as taxas de crescimento populacional apresentam-se positivas na maior parte dos bairros. De acordo com dados do IBGE (2010), a RA trabalhada possui densidade demográfica bruta de 290,22 hab/ha. Sendo que a densidade demográfica bruta que representa a intensidade da ocupação e do uso da infraestrutura urbana por uma população.

\section{RESULTADOS E DISCUSSÕES}

De acordo com Ferreira (2009), a RA de São Caetano possui densidade ocupacional progressiva no sentido norte, a partir dos espaços localizados próximos à região da Liberdade (RA IV). Nos bairros de Fazenda Grande do Retiro e São Caetano suas densidades se estabilizaram desde a década de 1980 em torno de $300 \mathrm{hab} / \mathrm{ha}$. A menor densidade, na faixa de 100 a $150 \mathrm{hab} / \mathrm{ha}$, que corresponde ao bairro de Campinas e Marechal Rondon, que, apresenta uma das maiores taxas de crescimento populacional da região. Nos bairros de Lobato e Alto do Cabrito, a 
situação é preocupante, pois as características geomorfológicas do sítio tornam qualquer ocupação de alto risco em razão da instabilidade do solo.

Analisando os dados de deslizamentos dos últimos anos (período de 2007 à 2012) da Defesa Civil - CODESAL, nota-se que a maior quantidade de deslizamentos ocorreu no ano de 2009 registrando um total de 368 ocorrências (tabela 1). Seguido do ano de 2010 que teve 229 ocorrências de deslizamentos, no ano de 2011 foram registrados 180 ocorrências.

Tabela 1 - Deslizamentos no período de 2007 a 2012 na Região Administrativa de São Caetano.

\begin{tabular}{|c|c|c|c|c|c|c|}
\hline Meses & 2007 & 2008 & 2009 & 2010 & 2011 & 2012 \\
\hline Janeiro & 3 & 0 & 0 & 0 & 1 & 1 \\
\hline Fevereiro & 4 & 5 & 0 & 2 & 0 & 1 \\
\hline Março & 0 & 15 & 1 & 8 & 5 & 0 \\
\hline Abril & 3 & 3 & 34 & 141 & 15 & 3 \\
\hline Maio & 3 & 19 & 275 & 43 & 18 & 27 \\
\hline Junho & 6 & 8 & 25 & 2 & 6 & 5 \\
\hline Julho & 5 & 2 & 8 & 27 & 0 & 9 \\
\hline Agosto & 3 & 0 & 1 & 3 & 1 & 1 \\
\hline Setembro & 0 & 1 & 3 & 0 & 1 & 0 \\
\hline Outubro & 1 & 3 & 18 & 0 & 10 & 0 \\
\hline Novembro & 0 & 2 & 3 & 1 & 122 & 0 \\
\hline Dezembro & 0 & 3 & 0 & 2 & 1 & 0 \\
\hline Total & 28 & 61 & 368 & 229 & 180 & 47 \\
\hline
\end{tabular}

Fonte: CODESAL, 2013. Organizado pelo autor, 2013.

Observando os dados da tabela 2, com a distribuição das ocorrências de deslizamentos por bairros pertencentes ao SIGA de São Caetano, com formatação condicional que utiliza uma escala de cores para identificar valores altos, médios e baixos para facilitar a visualização dos bairros com maiores ou menores ocorrências dentro da área em questão. As cores com maior destaque são as que possuem maiores ocorrências de deslizamentos no período em análise. 
O bairro de São Caetano aparece com maior destaque, tendo o ano de 2009, o de maior número de ocorrências, com 89. No mesmo ano Fazenda Grande do Retiro atingiu 51 ocorrências e Capelinha de São Caetano teve 43 deslizamentos, Campinas de Pirajá segue com 37, Marechal Rondon e Lobato com 25 seguindo com ocorrências menores nos demais bairros.

O bairro de São Caetano foi o que teve as maiores ocorrências de deslizamentos, no total levantado em 2010 registrou-se 45, em 2011 foram 38, em 2008 aparece com 13 ocorrências e em 2007 com registro de 9 deslizamentos. Somente no ano de 2012 o bairro com maiores deslizamentos não foi São Caetano, passando a ser Alto do Peru com 14 deslizamentos.

No ano de 2010, novamente o bairro destacado foi São Caetano com 45 ocorrências, na sequencia Fazenda Grande do Retiro com 29, Alto do Cabrito e Lobato com 24, Campinas de Pirajá com 23, Boa Vista do Lobato com 19 e outros bairros registraram menores ocorrências conforme tabela 02 .

Em 2011 com 38 ocorrências os bairros de São Caetano e Fazenda Grande do Retiro. E na ordem de maiores ocorrências Capelinha do São Caetano e Alto do Peru com 27 ocorrências, Boa Vista do São Caetano com 13, Lobato com 11 e os demais bairros com ocorrências menores de 6 (tabela 02). Alto do Peru em 2012 ocupou o maior número de deslizamentos com 14 registros, Marechal Rondon com 6 e os demais bairros com menores ocorrências registradas pela Defesa Civil de Salvador.

Os bairros de Plataforma, Jardim Lobato e Jaqueira do Carneiro apresentaram os menores incidentes de deslizamentos, somando apenas 6 ocorrências em cada bairro em todo período analisado. 
Tabela 2 - Ocorrências de deslizamentos / Bairros no SIGA III, no período de 2007 a 2012.

\begin{tabular}{|c|c|c|c|c|c|c|}
\hline \multirow[b]{2}{*}{ Bairro } & \multicolumn{6}{|c|}{ Ocorrências } \\
\hline & 2007 & 2008 & 2009 & 2010 & 2011 & 2012 \\
\hline São Caetano AR3 & 9 & 13 & 89 & 45 & 38 & 3 \\
\hline Capelinha de São & & & & & & \\
\hline Caetano & 4 & 7 & 43 & 15 & 27 & 2 \\
\hline Fazenda Grande do & & & & & & \\
\hline Retiro & 2 & 7 & 51 & 29 & 38 & 5 \\
\hline Campinas de Pirajá & 3 & 5 & 37 & 23 & 4 & 2 \\
\hline Marechal Rondon & 3 & 8 & 25 & 16 & 1 & 6 \\
\hline Boa Vista São & & & & & & \\
\hline Caetano & 4 & 3 & 17 & 15 & 13 & 5 \\
\hline Alto do Cabrito & 1 & 1 & 17 & 24 & 6 & 1 \\
\hline Lobato & 2 & 2 & 25 & 24 & 11 & 3 \\
\hline Bom Jua & 0 & 10 & 21 & 4 & 6 & 1 \\
\hline Alto do Peru & 0 & 0 & 10 & 4 & 27 & 14 \\
\hline Bela Vista do Lobato & 0 & 1 & 15 & 7 & 2 & 1 \\
\hline Boa Vista do Lobato & 0 & 4 & 10 & 19 & 4 & 1 \\
\hline Plataforma - AR3 & 0 & 0 & 2 & 3 & 0 & 1 \\
\hline Jardim Lobato & 0 & 0 & 2 & 0 & 3 & 1 \\
\hline Jaqueira do Carneiro & 0 & 0 & 4 & 1 & 0 & 1 \\
\hline Total & 28 & 61 & 368 & 229 & 180 & 47 \\
\hline
\end{tabular}

Fonte: CODESAL, 2013. Organizado pelo Autor, 2013.

CORRELAÇÃo do ÍNDICE PLUVIOMÉTRICO DE SALVADOR E AS OCORRÊNCIAS DE DESLIZAMENTOS NA REGIÃO ADMINISTRATIVA DE SÃO CAETANO

De acordo com a classificação de Köppen, o clima de Salvador é do tipo Af, sendo então clima quente e úmido com precipitações durante todo o ano entre 1300 a $2300 \mathrm{~mm}$. O principal período de chuvoso ocorre nos meses de abril a junho, 
período explicado pela interação de circulação de brisa terrestre com os ventos alísios predominantes de Leste a Sudeste (TANAJURA 2010).

Analisando os dados dos totais mensais pluviométricos das nove estações instaladas na cidade de Salvador comparando-os com os dados de deslizamentos, observa-se que os meses mais propícios a ocorrer deslizamentos coincidem com o período chuvoso da região em que Salvador está inserido, que são os meses de Março, Abril, Maio, Junho e Julho.

No ano de 2007, foram registrados poucos deslizamentos na região da São Caetano, com 6 no mês de maio e total de 28 deslizamentos, a menor quantidade de ocorrências no período analisado (figura 2).

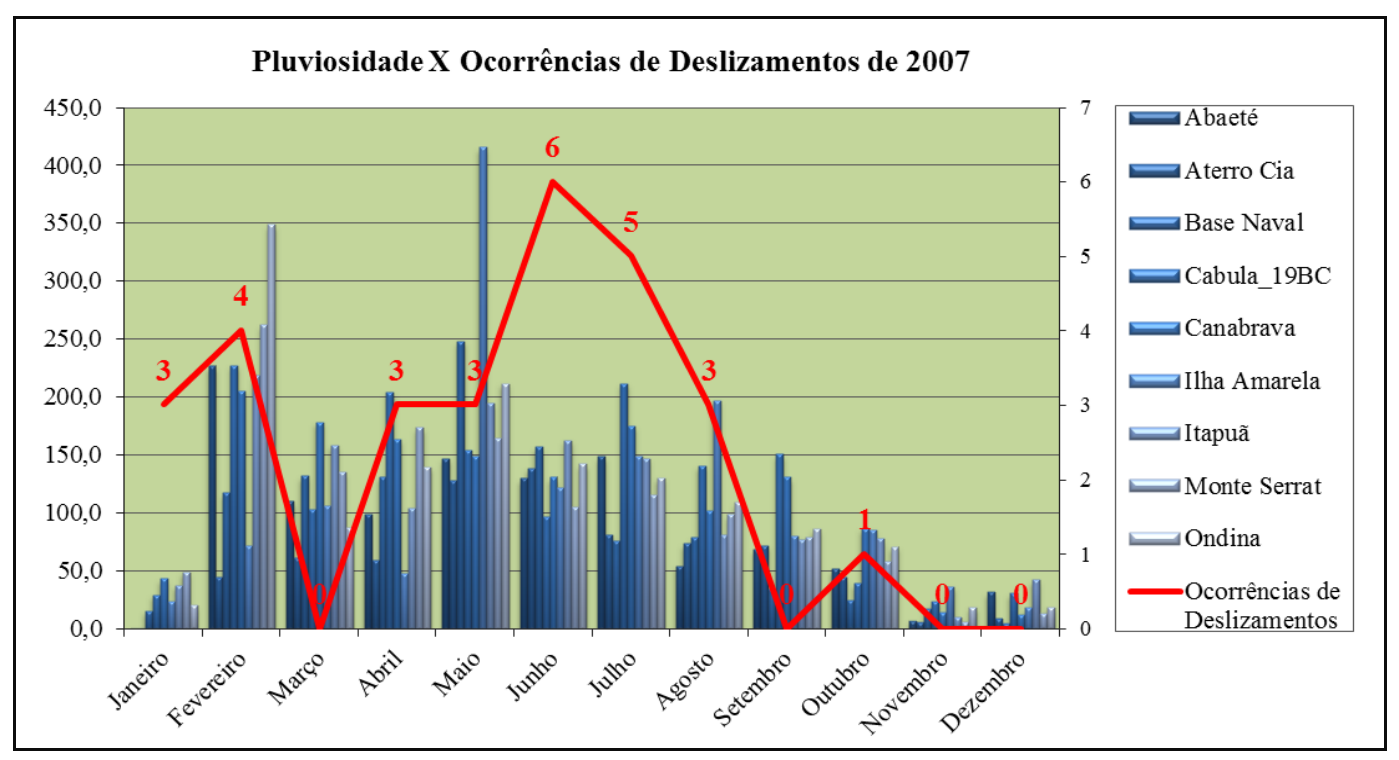

Figura 2 - Pluviosidades X Ocorrências de Deslizamentos da RA de São Caetano no ano de 2007. Fonte: CODESAL, 2013. INEMA, 2013. Organizado pelo Autor, 2013.

O gráfico a seguir (figura 3), correspondente aos deslizamentos de 2008, percebe-se que os meses de março e maio obtiveram maiores ocorrências, com 15 e 19 respectivamente. Assim como apresentaram os meses com maiores índices pluviométricos, sendo que no mês de março registrou-se total máximo de 230,0 e no mês de maio total máximo de 390,0. 


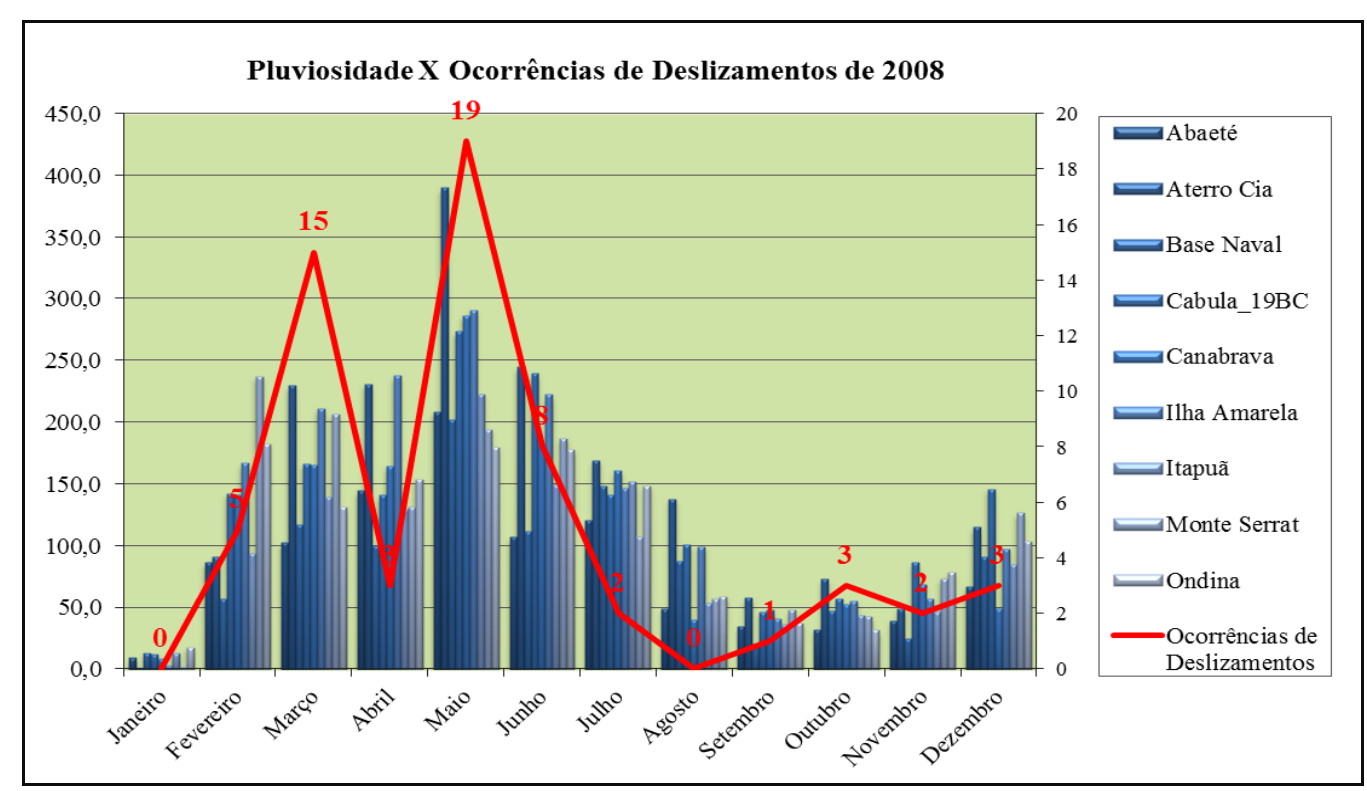

Figura 3 - Pluviosidades X Ocorrências de Deslizamentos da RA de São Caetano no ano de 2008. Fonte: CODESAL, 2013. INEMA, 2013. Organizado pelo Autor, 2013.

Relacionando os dados históricos de pluviosidade e de ocorrências de deslizamento do ano de 2009 (Figura 4), observa-se um aumento nas ocorrências de deslizamentos no mês de maio, totalizando 275 ocorrências de deslizamentos com total pluviométrico máximo registrado na estação Aterro Centro Industrial de Aratu - CIA de $872,6 \mathrm{~mm}$. O mês de abril teve 34 registros de deslizamentos no SIGA III de São Caetano.

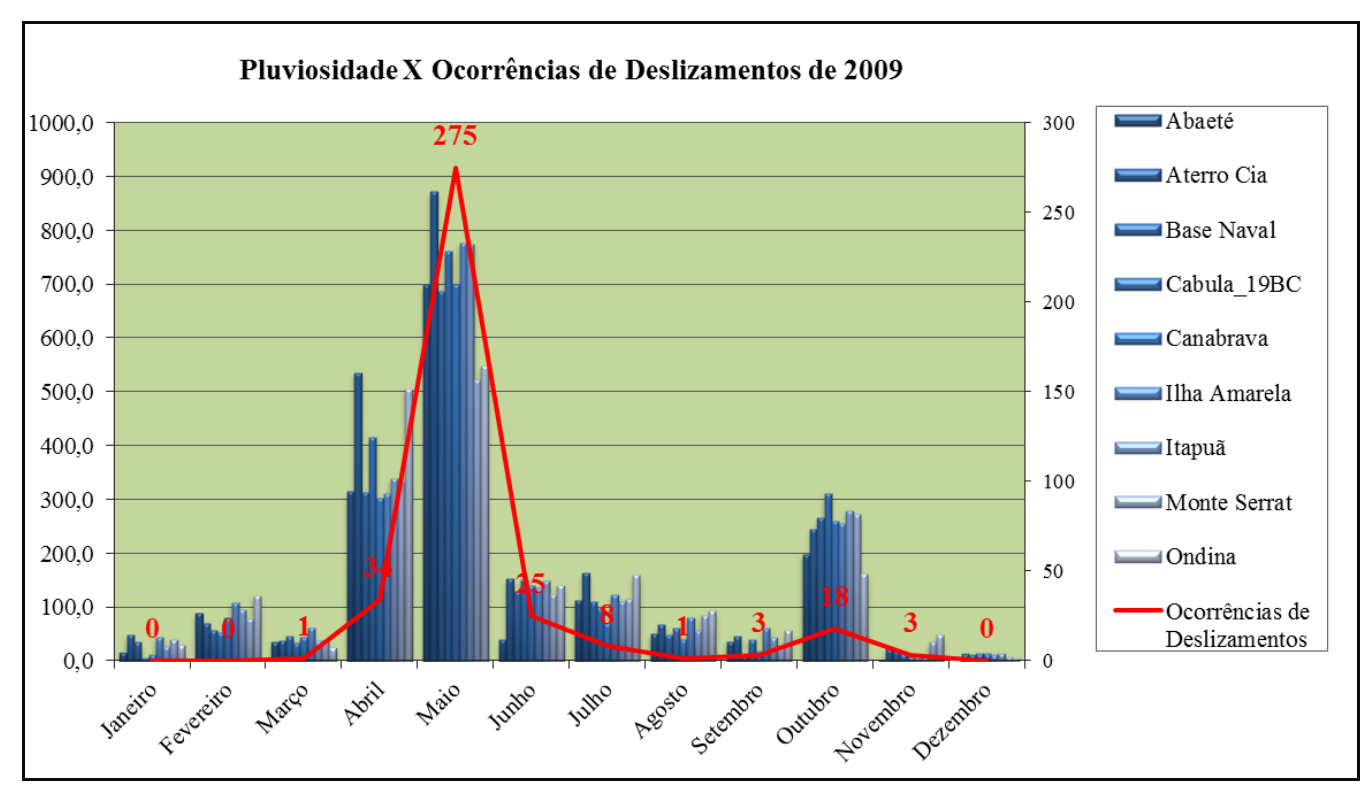

Figura 4 - Pluviosidades X Ocorrências de Deslizamentos da RA de São Caetano no ano de 2009. Fonte: CODESAL, 2013. INEMA, 2013. Organizado pelo Autor, 2013. 
A maior quantidade de ocorrências de deslizamentos registradas na região de São Caetano no ano de 2010 (gráfico 4) ocorreu no mês de abril, coincidindo com o período de maior índice pluviométrico registrado, com total máxima na estação de Aterro Cia de $853,00 \mathrm{~mm}$. O mês de Julho registrou o segundo maior índice pluviométrico, porém não corresponde a segunda maior ocorrência de deslizamentos que foi registrada no mês de maio com 43 ocorrências e o mês de julho teve 27 ocorrências.

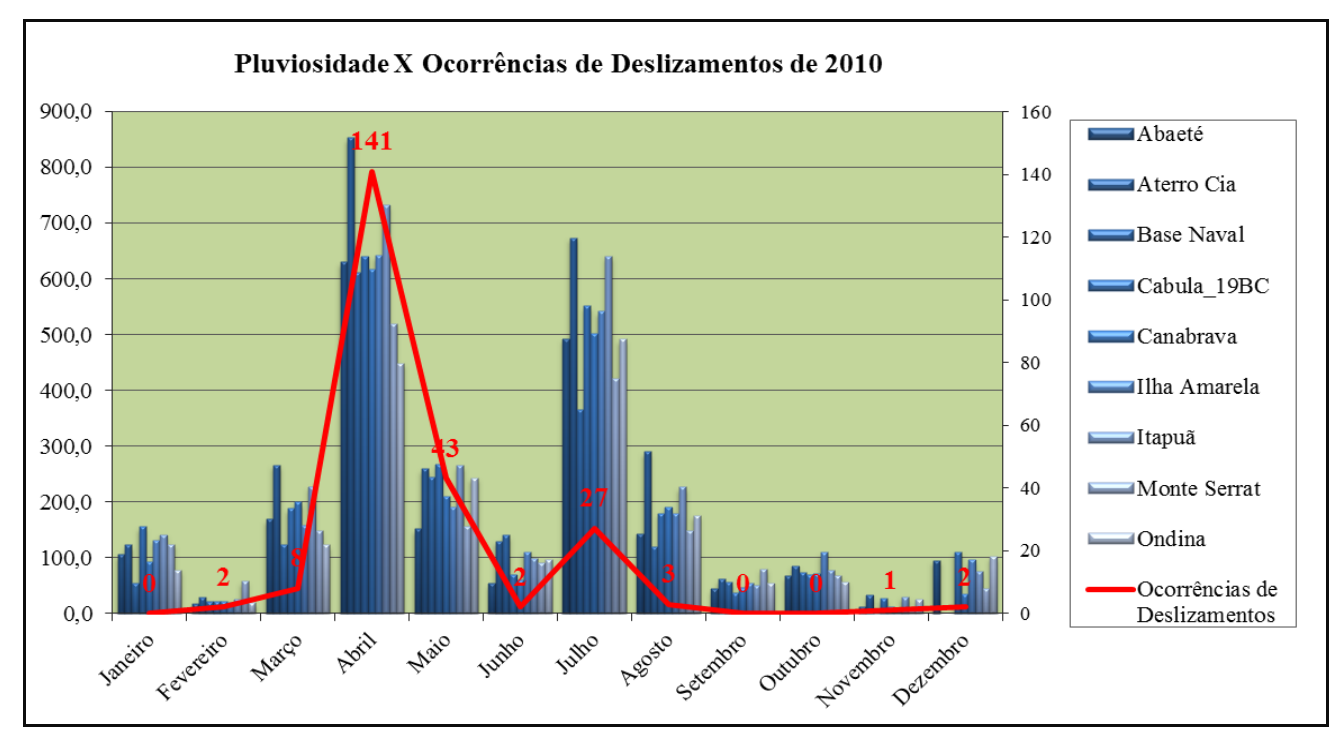

Figura 5 - Pluviosidades X Ocorrências de Deslizamentos da RA de São Caetano no ano de 2010. Fonte: CODESAL, 2013. INEMA, 2013. Organizado pelo Autor, 2013.

Com a correlação dos dados de pluviosidade e de ocorrências de deslizamentos do ano de 2011 (figura 6), podemos relatar que esse ano foi atípico devido a mudanças nas tendências de ocorrências. $O$ mês de novembro teve o maior número de ocorrências registrado, com 122 deslizamentos na região de São Caetano, seguidos de 18 no mês de maio e 15 no mês de abril. Portanto, no ano de 2011 o maior período de ocorrências de deslizamentos, não correspondeu aos meses de maiores índices pluviométricos na cidade de Salvador. 


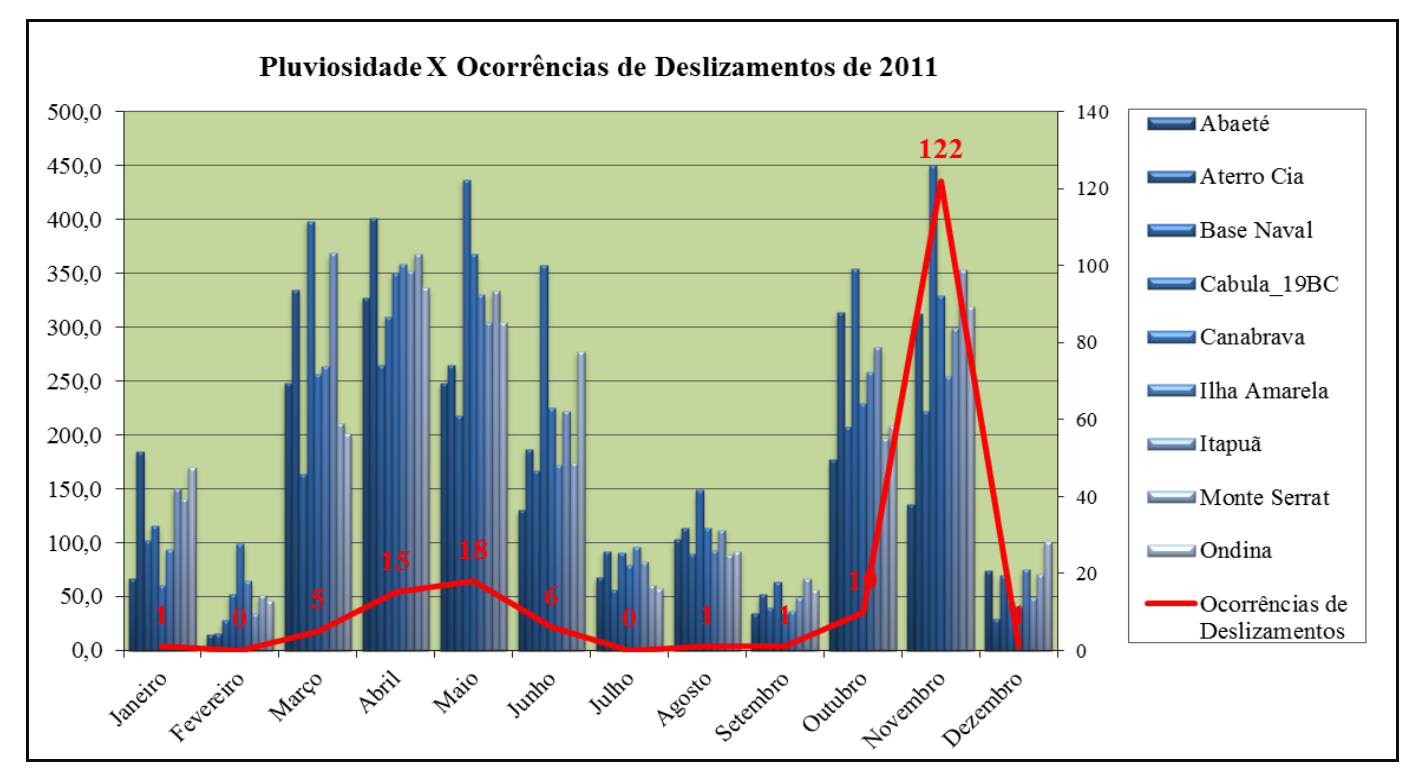

Figura 6 - Pluviosidades X Ocorrências de Deslizamentos da RA de São Caetano no ano de 2011. Fonte: CODESAL, 2013. INEMA, 2013. Organizado pelo Autor, 2013.

No ano de 2012, o maior número de ocorrência está concentrado no mês de maio com 27 deslizamentos, seguido de Julho com 9 ocorrências e comparando com os outros anos em análise foi o ano que obteve o segundo menor número de ocorrências na região de São Caetano.

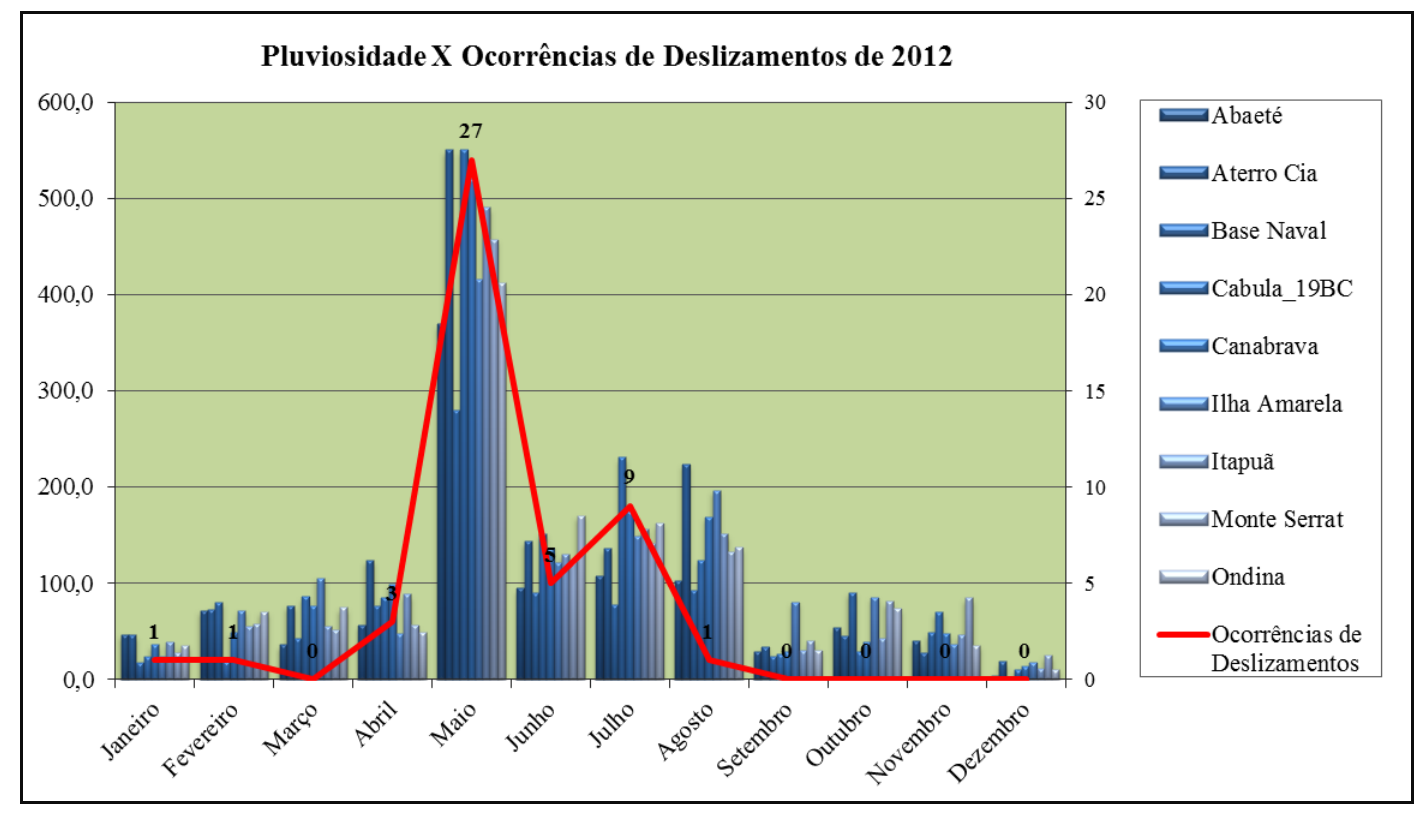

Figura 7 - Pluviosidades X Ocorrências de Deslizamentos da RA de São Caetano no ano de Fonte: CODESAL, 2013. INEMA, 2013. Organizado pelo Autor, 2013. 
Percebe-se na maioria dos gráficos apresentados, um comportamento de estreita relação da pluviosidade com os deslizamentos ocorridos na região em estudo. É importante salientar que, os impactos oriundos dos deslizamentos, não estão somente relacionados com períodos de intensa pluviosidade, mas também a enorme quantidade de ocupações irregulares na região, a falta de saneamento básico, de infraestrutura adequada, a quantidade de lixo jogado pela população nas encostas que consequentemente aumentarão as áreas propícias a deslizamentos.

\section{CONSIDERAÇÕES FINAIS}

Os resultados obtidos no desenvolvimento desse trabalho mostram que a maior parte dos deslizamentos ocorre em períodos com altos índices pluviométricos entre os meses de março a Julho. As causas desses deslizamentos, além das chuvas intensas, estão relacionadas às ações antrópicas modificando a morfologia das encostas.

Os impactos causados a população envolve problemas políticos e sociais, devido a falta de planejamento urbano e ambiental, falta de infraestrutura e a situação das construções nos locais propícios a deslizamentos. É notório que a cidade necessita de mudanças para reduzir os impactos surgidos com os deslizamentos, em que a população que sofre é a que possui menor poder aquisitivo e que na maioria das vezes acabam perdendo muitos bens materiais e deixando em risco sua saúde e sua vida.

É necessário aplicação de políticas públicas eficientes na cidade do Salvador já que a maior parte dos bairros periféricos apresenta moradias irregulares, sujeitas a riscos de deslizamentos. Para tanto, necessita-se de medidas preventivas atuantes para impedir o aumento de deslizamentos, estímulo a criação de projetos para análise de riscos, prevenção e assistência nos períodos de maior pluviosidade, retirada de moradores nas áreas propensas a deslizamentos para reduzir os impactos gerados a população.

É importante investimentos em educação ambiental para a população começar contribuir para melhorar seu espaço em que vive estabelecendo melhor convívio do homem com a natureza. Assim, com a redução do lixo lançado sobre as encostas, a preservação das áreas de vegetação que ainda restam, diminuirá as 
áreas propensas a deslizamentos. Mas isso só será possível com a conscientização da população com ações afirmativas conjuntas dos órgãos públicos e governos.

\section{REFERÊNCIAS}

ALMEIDA, Lutiane Q.; PASCOALINO, Aline. Gestão de risco, desenvolvimento e (meio) ambiente: um estudo de caso sobre os desastres naturais de Santa Catarina. Universidade Estadual Paulista "Julio de Mesquita Filho". UNESP. Rio Claro, São Paulo. Disponível em:<htt://WWW.ceped.ufsc.br/site/default/files/ gestao de risco desenvolvimento e meio ambiente no Brasil >. Acesso em: 20 fev. 2013.

BITAR, Omar Y. (Coord.). Curso de geologia aplicada ao meio ambiente. São Paulo: [s.n.], 1995. 247 p. il. (Série Meio Ambiente).

BUSCH, Amarilis; AMORIM, Sônia. A tragédia da região serra no Rio de Janeiro em 2011: procurando respostas. ENAP, Casoteca de Gestão Pública, 2011.

CARVAlHO, Celso S.; GALVÃO, Thiago (Org.). Prevenção de risco de deslizamento em encostas: guia para elaboração de políticas municipais. Brasília: Ministério das Cidades; Cities Alliance, 2006.

COSTA, Jailton de Jesus; GIUDICE, Dante Severo. Fenômenos naturais e ação antrópica: problemática de Salvador-BA. Revista Geonorte, v. 2, n.4, p.477-486, 2012. Edição especial. Disponível em: <http:// http://www.revistageonorte.ufam.edu.br. html >. Acesso em: 18 fev. 2013.

CUNHA, Márcio A. (Coord.) Ocupação de encostas. São Paulo: Instituto de Pesquisa Tecnológicas, 1991.

FERREIRA, Maria das Graças. (Coord.). Uso e ocupação do solo em Salvador. Caderno da Cidade: Secretaria Municipal de Desenvolvimento Urbano, Habitação e Meio Ambiente- SEDHAM, Salvador, v. 1 n.1, ano 1, jun.2009. Disponível em:<http:// http://www.sim.salvador.ba.gov.br. html >. Acesso em: 24 de mar.2013.

GIUDICE, Dante Severo. Impactos ambientais urbanos: o exemplo do CalabarSalvador-Ba. Salvador: P \& A Editora, 2011.

GIRÃO, Osvaldo; CORRÊA, Antonio C. B.; GUERRA, Antonio J. T. Encosta urbanas como unidades de gestão e planejamento, a partir do estudo de área a sudoeste da cidade de Recife-Pe. Revista de Geografia: UFPE-DCG/NAPA, Recife, v.24, n.3, set-dez. 2007.

GUERRA, Antonio José Teixeira; CUNHA, Sandra Baptista. (org.). Impactos ambientais urbanos. Rio de Janeiro: Bertrand Russell, 2011. 
MARGARIDA, Caroline; NASCIMENTO, Cristiane Aparecida. Manual de defesa civil. Florianópolis: CEPED/UFSC, 2009. Disponível em: <http:// http://www.defesacivil.sc.gov.br/ . html >. Acesso em: 26 de mar.2013.

OLIVEIRA, Luís Marcelo. Acidentes geológicos urbanos. Curitiba: MINEROPARServiço Geológico do Paraná, 2010.

ROSA FILHO, Artur; CORTEZ, Ana Tereza Caceres. Os deslizamentos de encostas nas favelas em área da "Suíça Brasileira". In: SIMPÓSIO DE PÓS-GRADUAÇÃO EM GEOGRAFIA DO ESTADO DE SÃO PAULO - SIMPGEO, 01., 2008, Rio Claro.

SANTOS, Ana Paula da Silva. Impactos da chuva sobre as habitações autoconstruídas em encostas da cidade do Salvador. 2010. 66 f. Trabalho de Conclusão de Curso (Monografia)-Escola de Engenharia, Universidade Católica, Salvador, 2010.

SANTOS, Rosely Ferreira dos (org.). Vulnerabilidade ambiental. Brasília: Ministério do Meio Ambiente, 2007.

SOUZA, Adeline Cerqueira; et al. Análise das encostas no bairro de São Caetano. [2012]. No prelo.

TANAJURA, Clemente A. S. et al. Mudanças Climáticas e Recursos Hídricos na Bahia: Validação da Simulação do Clima presente do Hadrm3p e comparação com os cenários A2 e B2 para 2070 - 2100. Revista Brasileira de Meteorologia, v.25, n.3, 345-358. Set. 2010.

TOMINAGA, Lídia Keiko; SANTORO, Jair; AMARAL, Rosangela do (Org.) Desastre natural: conhecer para prevenir. 2 ed. São Paulo: Instituto Geológico, 2012.

(Recebido em 25.09.2013; Aceito em: 27.06.2014) 